\title{
Information \& Communication Explosion of Knowledge Economy with Special reference to Cultural Imperialism
}

\author{
Dr. Khalid Sultan \\ Assistant professor, Department of Communication Studies \\ College of Applied Sciences, Nizwa, \\ Ministry of Higher Education, Sultanate of Oman \\ E-mail: khalid_sultan.niz@cas.edu.om \\ Dr Mirza Jan \\ (Corresponding Author) \\ Associate professor, Department of Mass Communication \\ Gomal University, D. I. Khan, Pakistan \\ E-mail: mirzajan_70@yahoo.com
}

Accepted: August 05, 2012 Published: September 22, 2012

Doi:10.5296/ijld.v2i5.2316

URL: http://dx.doi.org/10.5296/ijld.v2i5.2316

\begin{abstract}
This paper focuses on the information and communication which codify the knowledge capacity. It also discusses the explosion of knowledge economy and its intensity. This paper describes the overall structure of economics. Explosion is creating the salient characteristics of the human information landscape. Information and knowledge add value to basic products manufacturing and services are becoming increasingly integrated into complex chains of creation, production and distribution. This paper reflects the omnipotent of cultural imperialism. Sample of randomly selected students was relatively young and well educated of Gomal University. Sampling techniques was strictly confined to a small sample of cross-sectional survey. It implies an acceleration of the rate of growth of stocks of accessible knowledge, with positive implications for economic growth. WWW "Google" "Yahoo", "MSN" and "AltaVista" found correlated.
\end{abstract}

Keywords: Cultural Imperialism, Explosion, Information \& Communication, Knowledge Economy 


\section{Introduction}

Information and communication technologies have greatly reduced the cost and increased the capacity of organizations to codify knowledge, process and communicate information. However, There is now persuasive evidence that the information and computer technology (ICT) investment boom of the 1990's has led to significant changes in the absolute and relative productivity performance of firms, sectors and countries' (Hughes and Morton 2005, p-3). There are a number of sources of knowledge in government, for example, (a) ministers, (b) legislators, (c) civil servants, (d) documents - files, agenda, records of proceedings, minutes, government orders (GOs), notifications, (e) laws, rules and regulations, (f) archives, (g) embedded in physical systems, and (h) citizens and non-citizens (say, tourists). These sources are not only widely dispersed but also exhibit a great variety in content.

The Knowledge Economy is emerging from two defining forces: the rise in knowledge intensity of economic activities, and the increasing globalization of economic affairs. The rise in knowledge intensity is being driven by the combined forces of the information technology revolution and the increasing pace of technological change. Globalization is being driven by national and international deregulation, and by the IT related communications revolution. However, it is important to note that the term 'Knowledge Economy' refers to the overall economic structure that is emerging, not to any one, or combination of these phenomena (Sheehan, 1998). The other main driver of the emerging knowledge economy is the rapid globalization of economic activities. While there have been other periods of relative openness in the world economy, the pace and extent of the current phase of globalization is without precedent (Sheehan, 1998).

\section{2 information revolutions}

The IT revolution has intensified the move towards knowledge codification, and increased the share of codified knowledge in the knowledge stock of advanced economies. All knowledge that can be codified and reduced to information can now be transmitted around the world at relatively little cost. Hence, knowledge is acquiring more of the properties of a commodity. Market transactions are facilitated by codification, and the diffusion of knowledge is accelerated. Codification is also reducing the importance of additional, duplicative investments in acquiring knowledge. It is creating bridges between fields and areas of competence and reducing the 'dispersion' of knowledge. These developments promise an acceleration of the rate of growth of stocks of accessible knowledge, with positive implications for economic growth.

\section{3 knowledge, skills and learning}

Information and communication technologies have greatly reduced the cost and increased the capacity of organizations to codify knowledge, process and communicate information. As access to information becomes easier and less expensive, the skills and competencies relating to the selection and efficient use of information become more crucial, and tacit knowledge in the form of the skills needed to handle codified knowledge becomes more important than ever. Information and communication technology investments are complementary with investment in human resources and skills (Soete, 1997). The skills required of humans will increasingly be those that are complementary with information and communication technology; not those that are substitutes. Whereas machines replaced labor 
in the industrial era, information technology will be the locus of codified knowledge in the knowledge economy, and work in the knowledge economy will increasingly demand uniquely human (tacit) skills such as conceptual and inter-personal management and communication skills. The conversion of telecommunication (telecom) networks and all forms of communication and information content to digital standards is creating an electronic network foundation that facilitates exchanges and transactions of all kinds. Electronic commerce and the next generation Internet represent the next step in this process.

\section{Objectives of the Study}

1. to know the information and communication role in knowledge economy

2. to see the IT revolution

3. to know the knowledge, skill \& learning

4. to explore the notion of cultural imperialism

\section{Theoretical Framework}

Knowledge is a human right and a means to overcome many of the difficulties and obstacles facing mankind. "Knowledge" to embrace all forms of a society's epistemological and cultural assets and views it as a major organizing principal of holistic human development. Knowledge in this sense seeks to expand options and opportunities available to the individual. The connotations of the term "knowledge" in "knowledge society" differ from those in "knowledge economy" and "Information technology." Similarly, the term "information" is not the theoretical equivalent of the term "knowledge," since "knowledge" implies more than the mere quantity of information and data gathered. This explosion is creating the salient characteristics of the human information landscape the images that today are establishing a new world and a new society.

\section{1. knowledge-driven economic growth}

A natural starting point for gaining an increased theoretical understanding of the emerging knowledge economy is the new endogenous growth theory, which emphasizes the role of the stock of accumulated knowledge and the growth of this stock. It suggests that continuous increases in technological knowledge (Romer, 1990) or in human capital accumulation, i.e. the embodiment of knowledge in human beings (Lucas, 1988) are the driving force behind economic growth. However, it takes for granted that economic growth is not emerging automatically as 'manna from heaven', but is the result of deliberate actions and choices of various stake-holders, including the government (Nijkamp, 2003). Lucas' conceptualisation of the process by means of which human capital is built up is simple and founded on straightforward principles. Economic agents decide according to their preferences about the allocation of their non-leisure time between current production and the accumulation of human capital, and thereby they also determine the growth rate of output. If the time spent on current production is reduced, current output is reduced but at the same time the decision speeds up the formation of human capital and thus increases future growth.

\subsection{Hypotheses}

- Information \& communication Tech is more likely the result of knowledge economy 
- Greater is the knowledge economy, greater will be the cultural imperialism

\subsection{Main concepts}

1. Information \& communication: conceptually it reflects the networks and all forms of communication and information content to digital standards.

Operationally it stands for stock of accumulated knowledge and the growth of this stock.

2. Knowledge Economy: Conceptually it refers to the rise in knowledge intensity of economic activities, and the increasing globalization of economic affairs.

Operationally it implies an acceleration of the rate of growth of stocks of accessible knowledge, with positive implications for economic growth.

3. Cultural imperialism: It is across border view cultivate western values in different cultures around the world is an example of cultural imperialism.

\section{Literature Review}

Literature, review the commonly held notion that a knowledge economy is a services economy is dangerously misleading. As information and knowledge add value to basic products manufacturing and services are becoming increasingly integrated into complex chains of creation, production and distribution. At the core of the economy are goods producing industries, linked into value chains which see inputs coming from knowledge-based business services and goods related construction and energy industries, and outputs going to goods related distribution service industries. The Internet has been one of the most rapidly adopted communication technologies. The Internet is consuming an average of 150,685 new users per day, or 1.74 per second. By 2000, 250 million people will have access to the Internet (Killen \& Associates, 1996). More specifically, this paper aims to question the charge of "cultural imperialism on the Internet" in the globalizing media environments. One of the well-fitted theoretical perspectives applied to studying the effects of new electronic media is the cultural imperialism argument because of the problem of unequal flow of media content has been one of the major international issues. Individuals and governments around the globe have expressed concern regarding the influence of Western cultural products on both local and national cultures (Herschlag, 1996). Often expressed in the term of "cultural imperialism," this concern has become a topic of debate in not only scholarly circles, but in economic, legal and legislative arenas as Top of Form Bottom of Form Top of Form Bottom of Cultural Imperialism Argument.

Scholars, such as Schiller (1981) and Hamelink(1990), have maintained that despite the advent of our current information society, information itself and its technology have remained in the hands of the economic elite. This criticism is most commonly expressed in terms of "Core and Periphery Theory" which maintains that global imbalances exist between "core" (i.e., rich and industrialized nations of the First World) and "periphery" nations (i.e., poorer and rural countries of the Third World), in both the flow of media products and information. In this view, information and its technology are controlled by the core nations, and its flow is seen as uni-directional from the core to the periphery, with little opportunity for peripheral nations to participate in the process (Hamelink, 1990). To explore the globalization phenomenon and charges of cultural imperialism, it is important to draw together results and some of the basic assumptions and areas for criticism in the cultural imperialism argument - in terms of media power and its role in society. 
In regard to media power, the cultural imperialism argument offers an almost omnipotent view of the media that cannot be thoroughly justified. What it offers in terms of the media's power to affect cultural change is a dominance and transmission-based model, which seems implausible in the pluralistic and ever-expanding mediascape (Sims, 1995). However, what makes sense in regard to certain aspects of the debate such as the conglomeration of ownership and possibly formatted content, doesn't apply in terms of new media technology, the audience and effects. While one-way flow may be evident in terms of information flows on an information theory quantitative estimate, the reality is that as media technology and economies become more intertwined, this seemingly one-way flow reverses itself into a two-way flow in which what sells abroad influences what Americans see at home (McQuail, 1994). Cultural imperialism also makes a definite assumption of the media's role in and its influence on society. What emerges is a view of media and technology that is highly deterministic and devalues the role and importance of the cultural aspects of this argument (Ferguson, 1992). What then must the imperialist argument make of the media message? Sepstrup(1989) answers this question by reminding us that the path from transmission to cultural consequence is much more complicated in the international sphere. Even assuming the homogenization of media messages due to concentrated ownership or Western bias, cultural imperialism denies the power of the audience to interpretation of messages, contexts or to form its own meanings from the message (Smith, 1990). Elaborating on this idea, Straubhaar(1991) re-asserts the concepts of Active Audience Theory and a preference among cultures to view regional or national media products. Straubhaar(1991) draws on the past research and predictions of Pool(1977) and Read(1976) that local cultural producers would eventually begin to compete with American products, and as these productions increase and become more readily available, audiences would prefer regional or national products to international products. Two trends in research are used by Straubhaar to support Pool's predictions: 1) uses and gratification research in terms of its selectivity and 2) the active participation in terms of interpreting media content. In arguing the active audience perspective, Straubhaar quotes Fiske(1987) who said, "These audiences actively read television in order to produce from it meanings that connect with their social experience." Another possible criticism for the cultural imperialism argument lies in its equation of culture with consumerism and again denies the complexities of cultural development. According to Ferguson (1992), "Global Cultural Homogeneity" as a myth must presume a global cultural economy that completely ignores local, regional or national influences.

Appadurai(1990) further addresses the new path of global cultural flows and ultimately questions the former core and periphery models through his conceptualization of interacting "disjuncture" or relationships within these flows. He conceives of global cultural flow in five dimensions: Ethnoscapes refer to the flow of peoples (immigrants, refugees, tourists and so on) throughout the globe as we become increasingly mobile. In Appadurai's model, there is no traditional core and periphery to be designated and as such represents the "non-isomorphic" paths in which culture now flows. Building on earlier discussion of core and periphery theory, Straubhaar (1991) criticizes recent assumptions that new technology would strengthen the imbalances of media or information flows around the globe. While new technology has opened doors for the influx of American cultural products, it has also increased national production as well as the development of specific genres taken from American models and re-created into distinctly Latin American genres. Straubhaar(1991) also credits the influence of First World influences for the "decreased cost and increased flexibility in television technology." This influence has allowed for a growing number of television producers throughout Latin America. Straubhaar (1991) takes the view that even 
within a "dependency" or "imbalance" situation, development can occur in the "periphery" nation.

According to McChesney (1996), two oppositional trends dominate the United States and global media and communication. On one hand, there have been both rapid corporate concentration and commercialization of media industries. On the other hand, newly developed computer and digital communication technologies can undermine the ability to control communication in a traditional hierarchical manner. The most dramatic development along these lines has been the Internet, which permits inexpensive, global, interactive, and mass computer communication, as well as access to a previously unimaginable range of information. However, until recently, mass communications researchers have overlooked not only the Internet but the entire field of computer-mediated communication, staying instead with the traditional forms of broadcast and print media that fit much more conveniently into models for appropriate research topics and theories of mass communication (Morris \& Ogan, 1996).

Morris and Ogan(1996) argue that if mass communications researchers continue to largely disregard the research potential of the Internet, their theories about communication will become less useful. According to them, a new communication technology such as the Internet offers a chance to develop and refine theories of mass communication through its very nature. The Internet plays with the source-message-receiver features of the traditional mass communication model, sometimes putting them into traditional patterns, sometimes putting them into an entirely new configuration. Internet communication takes many forms, from World Wide Web pages operated by major news organizations to Usenet groups discussing folk music. Sources of the messages can range from one person to a group of professionals in a World Wide Web page. The messages themselves can be traditional news stories created by a reporter and editor, stories created over a long period of time by many people, or simply conversation. The receivers, or audiences, of these messages can also number from one to potentially millions, and may or may not move from their role as audience members to producers of messages. It is one of the Internet's advantages that an audience member may also be a message producer (Morris \& Ogan, 1996).

The gates of the world are groaning shut. From marble balconies and over the airwaves, demagogues decry new risks to ancient cultures and traditional values. Satellites, the Internet, and jumbo jets carry the contagion (David Rothkop, 1997)

Demonstrating that the Internet is truly a global phenomenon, the same source shows that 2.37 million of these are international hosts connected to the Internet, representing 150 countries. In 1994, there was wide variation in the number of Internet hosts per 1,000 people, ranging from 14 in Finland to fewer than 0.5 in Korea (Quelch \& Klein, 1996). Currently, $90 \%$ of traffic world-wide on the Internet is in English. These, together with the following factors, have lead some to denounce the Internet as the most recent and most sinister facet of American cultural imperialism to emerge: the Internet is anchored in the United States; the vast majority of World Wide Web sites are based in the U.S and are in English; most software used to navigate the Internet is in English; and search engines are mostly in English (Herschlag, 1996). On the surface it would certainly appear that the United States has taken over through its cultural dominance on the Internet. Thus will the Internet be another source of cultural imperialism? Many nations express concern over cultural imperialism on the Internet. On the basis of the discussion above, the research questions for this article can be developed as follows: According to the cultural imperialism argument, will the Internet become another source of cultural imperialism? What are the main effects of the Internet on the periphery? $\square$ What are the advantages and limitations of adopting the cultural imperialism argument to examine the effects of the Internet? 
The ability to become a publisher is not merely a theoretical opportunity. Instead of the "one to many" communications model, the Internet allows "any to many" communication with a relatively low barrier to entry. The "any too many" model facilitates the creation of special interest groups, removing the barriers of time and distance in the individual communications with others (Selene, 1996). Third, the Internet thereby allows people to continue to participate in their "local" culture no matter where in the world they are. As the citizens of other nations connect to the Internet we will see the Internet as a tool for the preservation and celebration of culture (Brown, 1996). Fourth, related to the previous point is the fact the receiver or viewer of messages is not a passive listener; they actively seek information or entertainment - they "pull" information out rather than have it pushed at them. Fifth, linguistic uniformity, and with it cultural uniformity is not the inevitable and only way forward for the Internet.

Therefore, nations worried about the threats posed by the Internet to dilute or irradiate cultural identity may find their only recourse is to focus on the production and dissemination of their own cultural products on-line and the creation of chat rooms and bulletin boards in their own language. As Adeboye (2002) has revealed, much of the financial flow-over, 60 percent is speculative rather than developmental.

\section{METHOD \\ 5.1. Sample}

This was a cross-section study. Fifty male and 50 female post graduate students of Gomal University have been selected for face to face interview on random method of sampling. The items selected for inclusion in the questionnaire were determined through a review of the relevant literature. Closed-ended questionnaire of multiple choices was prepared. The sample of 100 randomly selected students was relatively young and well educated. Members were from ICIT, IER, Economic, Mass Communication, MBA, MPA, Law College, commerce, and English departments of the University. Confidentiality was protected of all respondents.

\subsection{Pilot study}

Based on the pre-test, the survey questionnaire was conducted. The pilot study was a rehearsal for the final study. It helps the researchers in eliminating, modifying and reshaping those questions which could affect the validity of the response, the vague questions, were changed. In this way final questionnaire was collected.

\subsection{Assumptions}

It was assumed that the target sample will answer questions honestly and with the perceived perception of the phenomena that Cultural imperialism is the practical aspect of social, cognitive level of the people and, brings changes into the social system of a society.

\section{Limitations}

Sampling techniques was strictly confined to a small sample of cross-sectional survey. Time and costs also limit this research. Sampling was limited to university students who may or 
may not have established Internet habits. This study would pave the path for a longitudinal survey and will promote more exploratory rather than analytical approach.

\section{Result}

Data was collected from 100 male and female students of Gomal University, D.I.Khan (Pakistan). For data analysis both descriptive and inferential techniques of Statistics have been applied. For easy understanding I have categorized the numerical information according to the nature of the question asked from the target sample. The category comprises the analysis through frequency distribution, chi-square, binomial/sign test and graphical description.

Chi-square test was applied for the measurement of the main concepts, WWW exposure and the results showed support for the H1 "Information \& communication Tech is more likely the result of knowledge economy"65 percent of the total sample reported that they exposed to Google and declared more informative, while Yahoo (40\%) and MSN (33\%) got second and third respectively. With P-Value $=0.001$, difference was significant. This result rejects the null hypothesis because the WWW bring changes in the existence culture of the people. These websites change the perceptual and co native level about the culture. The exposure of the users of the Internet websites enters into the world of "core" from "periphery".

$\mathrm{H} 2 \quad$ Greater is the knowledge economy, greater will be the cultural imperialism

The second hypothesis with the chance of observing either 67 or more successes, or 33 or fewer successes in dichotomous rating scale "No", in 100 trials. I have used a binomial test for its validation. Further this empirical investigation reveals the results that Internet changes our cognition, social system, relationships, and identity. P-Value and statistical significance: Chi squared equals 20.609 with 3 degrees of freedom. The two-tailed $\mathrm{P}$-value equals 0.0001 , by conventional criteria; this difference is considered to be extremely statistically significant. Result showed that internet brings significant change of cognitive, social system, relationships, and identity level. Cognition is the map of mind which flashes the foreign culture of life economy and the Internet very effectively cultivates the seeds into the minds of the people.

Table 1.1: Web sites

Correlations

\begin{tabular}{||l|l|l|l|l||}
\hline Categories & & $\begin{array}{l}\text { More } \\
\text { informative }\end{array}$ & $\begin{array}{l}\text { Less } \\
\text { informative }\end{array}$ & not informative \\
\hline $\begin{array}{l}\text { More } \\
\text { informative }\end{array}$ & $\begin{array}{l}\text { Pearson } \\
\text { Correlatio } \\
\mathrm{n}\end{array}$ & 1.000 & -.973 & -.968 \\
\hline & $\begin{array}{l}\text { Sig. } \\
(2-\text {-tailed })\end{array}$ & - & .027 & .032 \\
\hline & $\mathrm{N}$ & 4 & 4 & 4 \\
\hline $\begin{array}{l}\text { Less } \\
\text { informative }\end{array}$ & $\begin{array}{l}\text { Pearson } \\
\text { Correlatio } \\
\mathrm{n}\end{array}$ & -.973 & 1.000 & .891 \\
\hline & $\begin{array}{l}\text { Sig. } \\
(2-\text {-tailed })\end{array}$ & .027 &. & .109 \\
\hline & $\mathrm{N}$ & 4 & 4 & 4 \\
\hline
\end{tabular}




\begin{tabular}{||l|l|l|l|l||}
\hline $\begin{array}{l}\text { not } \\
\text { informative }\end{array}$ & $\begin{array}{l}\text { Pearson } \\
\text { Correlatio } \\
\mathrm{n}\end{array}$ & -.968 & .891 & 1.000 \\
\hline & $\begin{array}{l}\text { Sig. } \\
(2 \text {-tailed })\end{array}$ & .032 & .109 &. \\
\hline & $\mathrm{N}$ & 4 & 4 & 4 \\
\hline
\end{tabular}

* Correlation is significant at the 0.05 level (2-tailed).

Table 1. Indicated that the best www "Google" "Yahoo", "MSN" and "AltaVista" found correlated and the respondents' opined that all web sites were informative.

Table 2. Internet bring changes

Categories
Cognition
Social system
Relationships
Loses identity

Yes
40
23
10
19

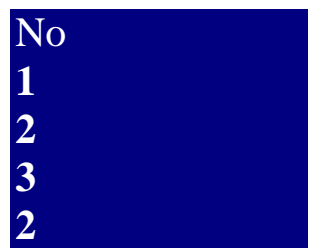

Finding have shown that majority $(40 \%)$ of the sample of the view that Internet changes cognitive level followed by "Social system (23\%) and 19\% respondents in the sample says "loses identity ". Only 10\% are of the opinion that Internet brings changes in relationships".

\section{Internet as an imperialistic tool of culture}

Number of saying "Yes"": were 67. Number of trials (or subjects) per experiment: 100 Sign test was applies. If the probability of "say" in each trial or subject is 0.500 , then:

The one-tail $\mathrm{P}$ value is 0.0004 , this is the chance of observing 67 or more say out of 100 trials.

The two-tail $\mathrm{P}$ value is 0.0009 . The observations reveal that internet is the powerful imperialistic tool of cultural change.

H0: There is significant increase exist in Internet culture change

Ha: There is no significant increase in Internet culture change

Chi-square $=47.0 \ldots \ldots \ldots \ldots$ degrees of freedom $=4 \ldots \ldots \ldots \ldots$ probability $=0.000$

Calculated value is greater (47.0) than tabled value (3.94). Where:

The degree of freedom is $\mathrm{df}=(\mathrm{R}-1)(\mathrm{C}-1)=4$, and the critical value (Table A.5 Portney \& Watkins) is $\alpha(0.05)$. We can reject null hypothesis. Therefore, it is concluded that Internet changes the existing culture. With the application of sign test the result showed that Internet change the local, information, contents of the media, language and, the culture of production.

\section{Significance of the findings}

This empirical study widens our understanding of the relationships between Internet and cultural imperialism. The results of this research signify the existence of increase that changes the culture and highlights the power of Internet. The core countries dominate the culture of the periphery through Internet.

\section{Conclusions}


The information revolution and the extraordinary increase in the spread of knowledge have given birth to a new era--one of knowledge and information which affects directly economic, social, cultural and political activities of all regions of the world. Governments worldwide have recognized the role that Information and Communication Technologies could play in socio-economic development. This study is necessarily limited in scope. Nonetheless, the current findings reveal some significant aspects in the field. This study is one of the initial attempts in this process in Pakistan. The researcher suggests future investigations on demographic variables in society, the sociological impact of internet on Pakistani family social activities. Internet confirms the cultural changes on cognitive as well as on social system, relationships and, identities. Furthermore, the information level should be investigated that how internet bring changes and how much it intervene in various field of information. It should be explored that how Internet dominate the local culture and why we lose our identities. These imbalances of flow between the industrialized and poor countries are widening and who are responsible for the erosion. The invasion of foreign culture set aside the local culture and how it can be stopped.

\section{References}

Adeboye, Titus. (2002). "Globalization: How Should Nigeria Respond"? NISER Occasional paper. No.2. Ibadan, Nigeria Institute of Social and Economic Research. pp. 2-9.

Appadurai A (1990). Disjuncture and difference in the global cultural economy. Theory, Culture \& Society, 7. 295-310.

Berlingeri I (1996). More cultural imperialism on the net. [Online].Available:http://roscoe.law.harvard.edu/HyperNews/get/courses/techseminar96-18/4/3 .html.

Berlingeri I Selene B Gokyigit E (1996). Cultural imperialism. [On-line]. Available:http://roscoe.law.harvard.edu/courses/techseminar96/course/sessions/culturalim perialism/intro.html.

Boddy W (1994). U.S.television abroad: market power and national introspection. Quarterly Review of Film and Video, 15(2), 45.

Brown C (1996) Cultural imperialism? No! [On-line]. Available:http://www.harvnet.harvard.edu/HyperNews/get/discussion/cult_imp2/2.html

Christian WT (1989). Cultural transfer or electronic imperialism?: The impact of American television programs on European television.

RothkopD (1997) Cultural Imperialism? Effects of Globalization on Culture. Managing director of Kissinger Associates and an adjunct professor of international affairs at Columbia University

Ferguson M (1992). The myth about globalization. European Journal of Communication, 7, 69-93. 
Giussani B (1997) France gets along with pre-web technology. Cybertimes: New York Times on the Web.

Hamelink C (1990) Information imbalance: Core and periphery in questioning the media: a critical introduction. London, Newbury Park: Sage.

Herschlag M (1996).Cultural imperialism on the net.

Available:http://www.harvnet.harvard.edu/vpr/tues.empire.html

Hughes, Alan and Michael S. Scott Morton (2005): ICT and Productivity Growth - The Paradox Resolved? Cambridge, MA, MIT Sloan School of Management, Working Paper 4579-05, November 2005 http://ssrn.com/abstract= 881797

Human Rights Watch (1996).Silencing the net: The threat to freedom of expression on-line. Cybertimes: New York Times on the Web.

Killen \& Associates (1996) Internet: Global Penetration 1996 and Forecast for the Year 2000 .

McChesney R W (1996). The Internet and U.S. communication policy-making in historical and critical perspective. Journal of Communication, 46(1), 98-126.

McLuhan M Powers B (1993).The global village: Transformations in world life and media in the 21st century. New York: Oxford University Press.

McQuail D (1994).Mass communication theory (3rd Ed.). London: Sage.

Meyrowitz J (1985) No sense of place. New York: Oxford University Press

Morris M \& Ogan C (1996).The Internet as mass medium. Journal of Communication. 46(1), 39-50.

Nijkamp, P. (2003), Entrepreneurship in a Modern Network Economy, Regional Studies $37,395-405$

Newhagen J E \& Rafaeli S (1996). Why communication researchers should study the Internet: A dialogue. Journal of Communication, 46(1), 4-13.

Petras J (1993) Cultural imperialism in the late 20th century. Journal of Contemporary Asia, 23(2), 139-148. Professor urges action against pornography in cyberspace. (1997, March 18). Korea Times.

Quelch J A, Klein LR (1996). The Internet and international marketing. Sloan Management Review. 60-75.

Romer, P.M. (1990), Endogenous Technological Change, Journal of Political Economy 98,71-102 
26)Salwen M B (1991) Cultural imperialism: a media effects approach. Critical Studies in Mass Communication, 8(1), 29-38.

Schiller H (1981) Who knows: Information in the age of the fortune 500. Norwood, NJ: Ablex.

Selene B (1996) Brief overview of French position. [On-line]. Available:

http://roscoe.law.harvard.edu/courses/techseminar96/course/sessions/culturalimperialism/Se lene.html

Soete, L. 1997, 'Macroeconomic and Structural Policy in the Knowledge-based Economy,' in Industrial Competitiveness in the Knowledge-based Economy: The New Role of Governments, OECD, Paris, p. 136.

Sepstrup P (1989) Research into international TV Flows. European Journal of Communication, 4, 393-408. Singapore sets internet rules. (1997, August 28). USA Today.

Sheehan, P. and Tegart, G. (Eds.) 1998, Working for the Future: Technology and Employment in the Global Knowledge Economy, Victoria University Press.

Sims R (1995) The United States vs. the world: A theoretical look at cultural imperialism. Available:http://www.utexas.edu/ftp/pub/eems/cultiimp.387._.html

Smith A D (1990) Towards a global culture? Theory, Culture \& Society, 7, 171-191.

34) Smith A D (1990) Media globalism in the age of consumer sovereignty. Gannett Center Journal, 1-17.

Straubhaar J D (1991). Beyond media imperialism: Asymetrical interdependence and cultural proximity. Critical Studies in Mass Communications, 8, 39-59.

Tomlinson J (1991) Cultural imperialism: a critical introduction. London: Pinter Publishers.

Wildavsky B (1996).Culture clashes. National Journal, 648-651.

Williams F Rice R E (1996).Communication research and the new media technologies. Communication Yearbook 7. Beverly Hills, CA: Sage. 